\title{
Adoption of internet of things among Malaysian halal agro-food SMEs and its challenges
}

\author{
${ }^{4}$ Ahmad Tarmizi, H., ${ }^{1,4 *}$ Kamarulzaman, N.H., ${ }^{2,4}$ Abd Rahman, A. and ${ }^{3,4}$ Atan, R. \\ ${ }^{1}$ Department of Agribusiness and Bioresource Economics, Faculty of Agriculture, Universiti Putra \\ Malaysia, 43400 UPM Serdang, Selangor, Malaysia \\ ${ }^{2}$ Department of Management and Marketing, Faculty of Economics and Management, Universiti Putra \\ Malaysia, 43400 UPM Serdang, Selangor, Malaysia \\ ${ }^{3}$ Department of Software Engineering and Information System, Faculty of Computer Science and \\ Information Technology, Universiti Putra Malaysia, 43400 UPM Serdang, Selangor, Malaysia \\ ${ }^{4}$ Halal Products Research Institute, Universiti Putra Malaysia, 43400 UPM Serdang, Selangor, Malaysia
}

Article history:

Received: 28 August 2019

Received in revised form: 3

November 2019

Accepted: 22 February 2020

Available Online: 26

February 2020

\section{Keywords:}

Agro-food SMEs,

Halal,

IoT,

Adoption,

Challenges

DOI:

https://doi.org/10.26656/fr.2017.4(S1).S26

\begin{abstract}
Safeguarding the high quality of halal food products is a new realm to explore with the advent of new technologies. The efficiency of food industry management has boosted the applicability of product traceability system with the aid of the internet of things (IoT). Traceability system with the use of IoT has facilitated food industry players in managing their product information along the supply chain. As one of the halal food industry key players, halal agro-food small and medium enterprises (SMEs) are reportedly yet to embrace the adoption of IoT. With IoT, halal agro-food SMEs supply chain has undoubtedly provided a trusted platform. However, halal related issues and scandals in the market are recurring persistently. Besides, the emergence of IoT in the agriculture sector requires active involvement by halal agro-food SMEs. Thus, the objective of this study was to investigate the adoption of IoT among Malaysian halal agro-food SMEs and its challenges. A self-administered questionnaire was employed to gather data from selected 158 halal agro-food SMEs. Descriptive analysis, mean score analysis, and Pearson correlation analysis were carried out to analyze the data. The results showed a lack of IoT adoption among halal agro-food SMEs in managing their business activities. The SMEs were also found to be low tech-savvy users of IoT in managing their halal products. Therefore, a vast improvement is needed in implementing IoT among Malaysian halal agro-food SMEs.
\end{abstract}

\section{Introduction}

Industrial technology has continued to evolve since the $18^{\text {th }}$ century with the introduction of steam power and mechanization in productions during the Industry 1.0, tailed by electricity and semi-automation computers control program. The world has since progressed towards Industry 3.0 with the advent of information and communication technology (ICT) and most recently, Industry 4.0. The concept of smart factories is expected to elevate further industrial efficiency, productivity, return on investment (ROI), technology convergence, and megatrends. Accordingly, any industry lagging without the help of technology will find it hard to achieve Industry 4.0. To ensure efficiency, high productivity, ROI, effective communication, and systematic information system are crucial. Paul (1996) described that information superhighway is very crucial and provides unlimited potential to a firm to compete in the world markets and the association of the internet and ICT will bring an explosion on business marketing activities (Hamill, 1997). The internet has been used by businesses for many years back and it is important for business growth and business value in the global markets (Feher and Towell, 1997; Hamill, 1997; Paul, 1996). In the global business environments, small and medium enterprises (SMEs) are utilizing more of ICT to gain competitive advantage and to support business activities (Ghobakhloo et al., 2011).

Industry 4.0 is a new era of ICT where information about real products is linked to the web-based application and integrated into the production process. Internet of things (IoT) is the key to Industry 4.0, 
integrating the production process among industry practitioners (Wilkesmann and Wilkesmann, 2018). IoT is an extended version of the internet by integrating mobile networks, internet, social networks, and intelligent things to provide better services or applications to users ( $\mathrm{Li}$ et al., 2016). IoT refers to a dynamic global network infrastructure where objects are connected, monitored, and optimized through wired, wireless, or hybrid systems (Zhang et al., 2017). IoT also has the possibility to connect people, goods, and operations through a global network and increasing global competitiveness (Del Giudice, 2016) and provides network connectivity in which it extends to objects, sensors, everyday devices to generate, exchange and consume data with minimum human intervention (Rose et al., 2015).

Internet of things (IoT) is a part and partial of ICT which is not only smart, but it is a combination of technologies and interaction across physical, digital, and biological domains (Nainy, 2017) and acts as an enabler for Industry 4.0. IoT helps lessen the implementation costs and provides platform for better tracking and tracing of food products ( $\mathrm{Li}$ et al., 2017), improve performance of supply chain (Zhang et al., 2017), provides a safe and trustworthy way of exchanging the information (Haddud et al., 2017), boosting data quantity and speed (Parry et al., 2016), and accelerate supply chain management (SCM) decision-making process (Rezaei et al., 2017). It also allows industry players to communicate effectively and efficiently for better and outstanding decision-making. It is also one of the effective ways of solving information management problems among industry practitioners (Yan et al., 2016). IoT not only facilitates companies to select potential suppliers through e-procurement, but also increase the efficiency of purchasing activities, enhance purchasing and searching processes, as well as provides relevant information on materials, and reduces human error (Kamarulzaman and Eglese, 2016; Kamarulzaman and Mohamed, 2013). Thus, IoT is all about smart devices connecting to each other using internet connectivity and storing information in the cloud available for access by the human to expedite decisionmaking, increase profit, and reduce waste and operation period.

In Malaysia, the emergence of halal food industry as an important business is mainly to deliver quality and value of halal food to consumers. For the past five (5) years, about 6,138 SMEs have been certified halal and in 2018 there are approximately 5,800 halal-certified SMEs, indicating a $6.7 \%$ decrease in the number of halal -certified companies (SME Corporation, 2018). The decrement scenario of halal-certified SMEs clearly indicated that there are loops in maintaining halal integrity among SMEs. With the presence of advanced technology such as internet of things (IoT), the halal integrity could be upheld among these SMEs. However, most SMEs are still underutilizing the potential value of the internet by restricting its application for basic management tasks (Ramdani et al., 2013). SMEs are yet to embrace new technologies such as information communication technology (Chibelushi and Costello, 2009; Bhaskaran, 2013), internet (Simmons et al., 2007; Marasini et al., 2008), and the latest innovation in IoT (Wilkesmann and Wilkesmann, 2018).

Various challenges of IoT adoption among SMEs such as lack of managerial skills and knowledge, inability to invest for new technologies, limited resources and experienced, untrained software application (Karipidis et al., 2009; Iskandar et al., 2012), lack of comprehension on IoT, vulnerabilities and security risk of IoT, loss of privacy, trust, and confidentiality (Haddud et al., 2017) and lack of understanding of advanced internet technologies (Kamarulzaman and Nawi, 2009). These challenges create tension between privacy and value of data sharing, weak policies, and inadequate practices to manage and control IoT (Dutton, 2014). Despite various challenges of adoption IoT among SMEs, the adoption of technology by SMEs can be improved by removing the challenges (Chibelushi and Costello, 2009).

Based on a study by Simmons et al. (2007), internet adoption among SMEs is vaguely understood. SMEs are also reportedly facing technological constraints in adopting IoT due to the lack of education and technical skills required to garner competitive advantage in the global marketplace (Tan et al., 2009). IoT is believed to be an effective business tool to uplift halal supply chain performance and increase halal product quality. However, halal agro-food SMEs are still slow in utilizing IoT in their production process as well as in the halal supply chain activities. Thus, the main objective of this study was to investigate the adoption of IoT among Malaysian halal agro-food SMEs and its challenges.

\section{Methodology}

Three main theories namely Theory of Diffusion of Innovation (DOI), Theory of Reasoned Action (TRA), and Technology Acceptance Model (TAM) are commonly used to measure technology adoption level across different industries (Molinillo and Japutra, 2017). In Theory of Diffusion of Innovation (DOI), Rogers (1995) argued that the adoption of innovation is influenced by a group of characteristics such as complexity, compatibility, trialability, and observability. 
Based on Parmentola et al. (2018), complexity is described as perceived difficulty of learning to use and understand the new technology where from SMEs context, understanding of new technology and learning to use the technology is the biggest concern since it implies the difficulty of innovation to be understood or used. Thus, based on DOI, knowledge of new technology is crucial for SMEs to adopt IoT.

Apart from DOI, Theory of Reasoned Action (TRA) commonly used and adopted in various studies such as SMEs technologies adoption intention (Hanafizadeh et al., 2012; Dang and Pham, 2018), predicting students' intention to adopt mobile learning (Buabeng-andoh, 2018), and acceptance of wireless internet ( $\mathrm{Lu}$ et al., 2003). Based on Al-ajam and Nor (2015), TRA considers a narrow perspective of only two variables (attitude and subjective norm) that may affect individuals' behavioral intention. Meanwhile Lada et al. (2009) indicated the personal in nature and the reflection of social influence are the two core aspects in TRA. Wallace and Sheetz (2014) explained that TRA model rests on an underlying assumption that the best predictor of an individual's behavior or an organization is the intention, which is highly determined by the attitude towards the performance and subjective norm associated with a behavior. Despite the various studies on the intention of adoption, TRA components however may be insufficient in the study related to individual behavior (Ajzen, 1991; Al-ajam and Nor, 2015).

While in Technology Acceptance Model (TAM), the theory stated that beliefs are determinants of individual intentions to adopt a technology (Davis, 1989). Two variables namely perceived ease of use (PEOU) and perceived usefulness (PU) are included in TAM. Perceived ease of use (PEOU) explains the degree to which an individual believes that using a system would be free of physical and mental effort while perceived usefulness (PU) explains the degree to which an individual believes that using a particular system would enhance his or her job performance (Dang and Pham, 2018). According to Lindsay et al. (2011), there is an extension of the Technology Acceptance Model (TAM) which is known as Technology Acceptance Model 2 (TAM2) and Technology Acceptance Model 3 (TAM3). An extended version of TAM2 by Venkatesh and Davis (2000) indicated the additional dimension of PU which explains social influences and cognitive instrumental processes. The category of social influence includes subject norms, voluntariness, image, and experience while the cognitive instrumental process includes elements such as job relevance and output quality. TAM3 proposed by Venkatesh and Bala (2008) discussed the general belief of technologies such as computer self-efficacy, perception of external control, computer anxiety, and computer playfulness. However, all the elements discussed in TAM2 and TAM3 still can be explained by using TAM, taking into consideration the two variables, PU and PEOU.

The conceptual framework of this study was developed based on the three main theories namely Theory of Diffusion of Innovation (DOI), Theory of Reasoned Action (TRA), and Technology Acceptance Model (TAM). Based on TAM, perceived ease of use (PEOU) and perceived usefulness (PU) are the two variables that provide significant measurement towards technology adoption study (Dang and Pham, 2018). Moreover, studies by Ibrahim and Mokhtarudin (2010); Ahmad Tarmizi et al. (2014); Ahmad Tarmizi, Kamarulzaman and Latiff (2014) indicated that knowledge aspects adapted from DOI could be a necessary element in the implementation of something innovative or new. In this study, five (5) main variables were identified in measuring IoT adoption among halal agro-food SMEs as illustrated in Figure 1. The hypotheses of this study were established as follows: -

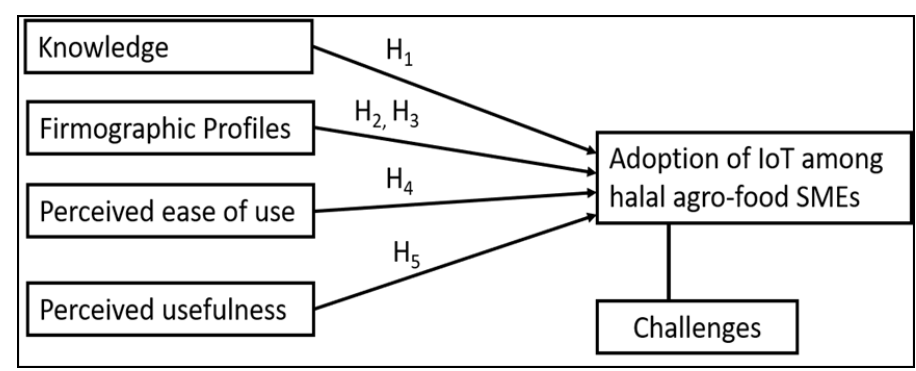

Figure 1. Conceptual Framework of IoT Adoption among Halal Agro-Food SMEs

Source: Rogers (1995); Ibrahim and Mokhtarudin (2010); Ahmad Tarmizi et al. (2014); Ahmad Tarmizi, Kamarulzaman and Latiff (2014); Dang and Pham (2018)

$\mathrm{H}_{0}$ : There is no relationship between knowledge level and the adoption of IoT among halal agro-food SMEs.

$\mathrm{H}_{1}$ : There is a relationship between knowledge level and the adoption of IoT among halal agro-food SMEs.

$\mathrm{H}_{0}$ : There is no relationship between annual sales and the adoption of IoT among halal agro-food SMEs.

$\mathrm{H}_{2}$ : There is a relationship between annual sales and the adoption of IoT among halal agro-food SMEs.

$\mathrm{H}_{0}$ : There is no relationship between the presence of Muslims workers and the adoption of IoT among halal agro-food SMEs.

$\mathrm{H}_{3}$ : There is a relationship between the presence of Muslims workers and the adoption of IoT among halal agro-food SMEs.

$\mathrm{H}_{0}$ : There is no relationship between perceived ease of use (PEOU) and the adoption of IoT among halal agrofood SMEs. 
$\mathrm{H}_{4}$ : There is a relationship between perceived ease of use (PEOU) and the adoption of IoT among halal agro-food SMEs.

$\mathrm{H}_{0}$ : There is no relationship between perceived usefulness (PU) and the adoption of IoT among halal agro-food SMEs

$\mathrm{H}_{5}$ : There is a relationship between perceived usefulness (PU) and the adoption of IoT among halal agro-food SMEs

By identifying displayed products with certified Malaysia halal logo, 158 Malaysian halal agro-food SMEs had been approached during an exhibition, Malaysia Agriculture, Horticulture and Agrotourism Show (MAHA) 2018 at Serdang, Selangor which was held in November 2018. A quantitative survey approach was employed using a self-administered questionnaire to gather data from selected 158 halal agro-food SMEs. Descriptive analysis was carried out to determine firmographic profiles while mean score analysis was employed to measure the knowledge level based on a calculated score from knowledge statements. There were 10 statements queried with three choices of answers ( $3=$ true, $2=$ not sure and $1=$ false) related to IoT. For each correct answer, a score of one (1) was given while an incorrect answer was given a zero (0) score. For those choosing 'not sure' as their answer, the score was also given zero (0) because this indicates a lack of knowledge by the respondents on the statement. There are varies knowledge scores based on the number of knowledge statements measured (Sanlier and Konaklioglu, 2012) thus, scores between 5-10 indicate a high level of knowledge while scores between 1-4 indicate a low level of knowledge.

Further, Pearson correlation analysis was used to analyze the relationship between knowledge level, annual sales, presence of Muslim workers, perceived ease of use (PEOU), perceived usefulness (PU) and adoption of IoT among halal agro-food SMEs. The analysis was also carried out to measure the direction and strength of the relationship. The direction of the relationship is indicated by whether it is negative, positive or zero whereas the strength of the relationship is indicated by $r$-value where $r$-value greater than 0.7 indicates a strong positive relationship (Rankin and Stokes, 1998).

\section{Results and discussion}

\subsection{Firmographic profiles of halal agro-food SMEs}

Table 1 shows the result of SMEs profiling. Out of 158, SMEs participated in this study, the majority of the Malaysian halal agro-food SMEs were from the Western region accounted for 65 (41.4\%) while 41 SMEs (25.9\%) were from the Northern region. The rest accounted for 32 SMEs $(20.3 \%)$ from the Southern region, 18 SMEs $(11.4 \%)$ were from the Eastern Region, and two SMEs $(1.3 \%)$ were from the states of Sabah and Sarawak. The majority of the respondents who provided their responses were from the marketing team (officer or promoter) of the company, accounted for 55 (34.8\%), followed by 35 $(22.2 \%)$ managers and $31(19.6 \%)$ owners of the company. The remaining respondents accounted for 22 $(13.9 \%)$ were from the operation line, 13 (8.2\%) executive, and $2(1.3 \%)$ assistant, respectively.

Table 1. Halal agro-food SMEs firmographic profiles

\begin{tabular}{llcc}
\hline \multicolumn{1}{c}{ Profiles } & Frequency (n) & Percentage (\%) \\
\hline \multirow{5}{*}{ State Region } & Northern & 41 & 25.9 \\
& Southern & 32 & 20.3 \\
& Eastern & 18 & 11.4 \\
& Western & 65 & 41.4 \\
& Others (Sabah and Sarawak) & 2 & 1.3 \\
\hline \multirow{5}{*}{ Representative } & Manager & 35 & 22.2 \\
& Executive & 13 & 8.2 \\
& Owner & 31 & 19.6 \\
& Marketing team & 55 & 34.8 \\
& Operation officer & 22 & 13.9 \\
& Assistant & 2 & 1.3 \\
\hline \multirow{2}{*}{ Muslim Workers } & Yes & 133 & 84.2 \\
& No & 25 & 15.8 \\
\hline \multirow{5}{*}{ Annual Sales } & Less than RM300,000 & 61 & 38.6 \\
& (Micro) & & 37.5 \\
& RM300,000 - RM3 million (Small) & 75 & 47.9 \\
& RM301,000 - RM20 million (Medium) & 22 & 13.9 \\
\hline
\end{tabular}

Note: $\mathrm{n}=158$ 
The majority of the halal agro-food SMEs (133, $84.2 \%$ ) hired Muslim workers while the rest of the SMEs (25, 15.8\%) hired both Muslim and non-Muslim workers. The presence of Muslim workers was paramount in maintaining halal integrity along the halal food supply chain and this corresponded to the minimum requirement of two Muslim workers according to the Department of Islamic Development Malaysia (JAKIM), Malaysian Standard (MS) for halal food handling (MS 1500:2010), as well as halal certification application in Malaysia. Absence of Muslim workers in halal agro-food SMEs production could compromise halal quality and integrity as a whole.

\subsection{Adoption of IoT among halal agro-food SMEs}

Table 2 shows that out of 158 respondents, 79 (50\%) of halal agro-food SMEs were considered as a low rate of electronic device utilization. These SMEs utilized basic electronic devices such as smartphones, laptops, and desktop for general usages like social networking and business information management. As indicated by Pipitwanichakarn and Wongtada (2019), this type of user is considered as late majority IoT category due to their low usage of electronic devices. The remaining 79 (50\%) halal agro-food SMEs were categorized as a high rate of electronic devices utilization which also considered as early adopters of IoT as they demonstrated the presence of smart devices and highly utilized those devices in managing their business activities. These SMEs were found to be actively utilizing a laptop, desktop, Wi-Fi, smartphone, wireless printer, and bar code scanner as their information and communication technology tools in managing their business activities. These SMEs used smart devices for emailing, online banking, managing business website, social networking and managing business through various accounting software. However, none of them utilizes smart devices in the production line area to gather and store information during production. It can show that the rise of the technology industry has led to the enormous presence of smart devices such as smartphones, tablets, computers, and other devices. According to Rose et al. (2015), it is expected that more than 50 billion users will be connected to smart devices by 2020 . Thus, the presence of electronic devices is among the important components of IoT application.

\subsection{Knowledge level on IoT}

There were ten items or statements constructed to measure knowledge level on IoT among halal agro-food SMEs. Knowledge aspect is an important and basic element of understanding of the new thing. All statements were developed based on a few references that provide insight discussion and explanation about knowledge of internet of things (Rose et al., 2015; Haddud et al., 2017). These statements were ranked according to the mean score as summarized in Table 3. The highest mean score statement (4.24) showed that halal agro-food SMEs in this study have an agreement and high understanding that IoT is useful in product tracking and tracing activities along the production line. The lowest mean score statement (3.65) showed that halal agro-food SMEs agreed that IoT adoption is the most practical approach to achieve halal integrity. The overall mean score for IoT statements was 3.842 (greater than 0.50), indicating that halal agro-food SMEs are quite knowledgeable about IoT.

Table 2. Type of electronic devices use among halal agro-food SMEs

\begin{tabular}{clccc}
\hline & & Frequency (n) & Percentage (\%) & Utilization Rate \\
\hline \multirow{2}{*}{$\begin{array}{c}\text { Type of electronic } \\
\text { devices use }\end{array}$} & Smartphone and computer & 46 & 29.1 & Low \\
& Smartphone & 33 & 20.9 & 25.3 \\
Smartphone, computer, wireless devices, and Wi-fi & 40 & 39 & 24.7 & High \\
\hline
\end{tabular}

Note: $\mathrm{n}=158$

Table 3. Mean ranking of halal agro-food SMEs knowledge on IoT

\begin{tabular}{lcc}
\hline Statement & Mean & SD \\
\hline IoT devices assist the company to track and trace products along the production line. & 4.24 & 4.138 \\
IoT devices facilitate the company in managing product information & 3.99 & 0.867 \\
IoT systems provide difficulties when the server becomes unavailable. & 3.93 & 0.845 \\
IoT devices improve the authentication of ingredients selected for production. & 3.85 & 0.831 \\
Halal supply chain traceability is efficient using IoT systems. & 3.81 & 0.815 \\
IoT increases efficiency among supply chain players in managing halal products. & 3.8 & 0.796 \\
IoT systems help in halal food supply chain trend analysis. & 3.79 & 0.837 \\
Information sharing by IoT devices can be 100\% trusted. & 3.7 & 0.796 \\
Our company is willing to invest in IoT systems for halal production. & 3.66 & 0.936 \\
IoT system is the most practical approach for halal supply chain integrity. & 3.65 & 0.903 \\
\hline Overall mean score $=3.842$ & &
\end{tabular}


Table 4 shows the result of halal agro-food SMEs' knowledge level on IoT based on score analysis, in which the score between 5-10 indicated a high knowledge level on IoT while the score between 1-4 indicated a low knowledge level on IoT. Based on the result, only $8(5.1 \%)$ of halal agro-food SMEs showed that they have a high knowledge level on IoT while the remaining $150(94.9 \%)$ of halal agro-food SMEs indicated that they have a low knowledge level on IoT. According to Brand and Huizingh (2008), the decision process of adopting new technology begins with awareness of the existence and learning of the new innovation. Since there were less than $10 \%$ halal agrofood SMEs who have a high knowledge level on IoT, there is still a long journey towards full adoption of IoT in halal agro-food SMEs supply chain. According to Simmons et al. (2007), awareness of IoT should be developed to prevent the negative perception of internet adoption among SMEs and so do knowledge (Ibrahim and Mokhtarudin, 2010). Knowledge was found to be very important to reduce complexity in implementing technology however, insufficient knowledge may create a huge barrier for implementing new technology (Iskandar et al., 2012). Therefore, formal education of IoT with halal knowledge skills and halal related training are crucial to develop the knowledge in order to achieve integrity in the halal industry (Rajendran and Kamarulzaman, 2019).

Table 4. Knowledge level among halal agro-food SMEs on IoT

\begin{tabular}{ccc}
\hline Level & Frequency $(\mathrm{n})$ & Percentage $(\%)$ \\
\hline High $(5-10)$ & 8 & 5.1 \\
Low $(1-4)$ & 150 & 94.9 \\
\hline
\end{tabular}

3.4 Relationship between knowledge level, firmographic profiles, perceived usefulness, perceived ease of use, and adoption of IoT among halal agro-food SMEs

There were five (5) hypotheses tested using Pearson correlation analysis to investigate the relationship between knowledge level, firmographic profiles, perceived ease of use (PEOU), perceived usefulness (PU), and adoption of IoT among halal agro-food SMEs in Malaysia. As shown in Table 5, the $r$-value for knowledge, annual sales, presence of Muslims workers, perceived ease of use (PEOU) and perceived usefulness (PU), adoption of IoT were $0.046,0.121,0.1090 .214$ and 0.214 , respectively. All values showed a positive sign indicating that knowledge level, annual sales, number of workers, perceived ease of use (PEOU), and perceived usefulness (PEOU), have positive relationships with the adoption of IoT. However, the $r$-value of all five tested variables showed value below 0.7 , indicating weak relationships. Based on level of significant value, both perceived ease of use (PEOU)(0.007), and perceived usefulness (PU)(0.007) were statistically significant at $1 \%$ level of significance respectively while knowledge level (0.567) and firmographic profiles such as annual sales (0.173) and presence of Muslims workers (0.131) were statistically insignificant.

The results indicated that there were significant relationships between perceived ease of use (PEOU) and perceived usefulness (PU) and adoption of IoT among halal agro-food SMEs, while there were no significant relationships between knowledge level, annual sales, and presence of Muslims workers with the adoption of IoT among halal agro-food SMEs in Malaysia. From the result, it can be concluded that the firm's size is not reliable to determine the adoption of IoT among halal agro-food SMEs. As Tan et al. (2010) described many SMEs in the Asia-Pacific region have yet to reap IoT benefits and Malaysia is one of the countries. This indicated that poor adoption of IoT among SMEs due to poor telecommunication infrastructure, inability to integrate the internet into business processes, limited internet literacy, high costs of internet equipment, incomplete government regulations for e-commerce, or poor understanding of the dynamics of the knowledge economy (Marasini et al., 2008; Chibelushi and Costello, 2009).

\subsection{IoT challenges among halal agro-food SMEs}

Challenges of IoT related statements were asked to halal agro-food SMEs. The results revealed that less than $50 \%$ of the total agro-food SMEs were willing to share their thoughts over the challenges of adopting IoT in their daily operations. Table 6 shows the general challenges faced by halal agro-food SMEs in

Table 5. Relationship between knowledge, firmographic, perceived ease of use, perceived usefulness and adoption of IoT among halal agro-food SMEs

\begin{tabular}{lccc}
\hline & Pearson correlation $(r)$ & Sig. (2-Tailed) & Decision \\
\hline Knowledge & 0.046 & 0.567 & Fail to reject $\mathrm{H}_{0}$ \\
Annual sales & 0.121 & 0.173 & Fail to reject $\mathrm{H}_{0}$ \\
Presence of Muslims workers & 0.109 & 0.131 & Fail to reject $\mathrm{H}_{0}$ \\
Perceived ease of use (PEOU) & 0.214 & $0.007 *$ & ${\text { Reject } \mathrm{H}_{0}}^{*}$ \\
Perceived usefulness (PU) & 0.214 & $0.007^{*}$ & Reject $\mathrm{H}_{0}$ \\
\hline
\end{tabular}

Note: *Correlation is significant at $1 \%$ level of significance (2-Tailed) 
Table 6. Challenges of IoT among halal agro-food SMEs

\begin{tabular}{lcc}
\hline Challenges & Frequency (n) & Percentage (\%) \\
\hline Difficulties in getting trusted information on raw materials from suppliers. & 15 & 9.4 \\
IoT is not suitable to be implemented by small and medium enterprises. & 7 & 4.4 \\
A high concern about IoT information security. & 5 & 3.1 \\
A high cost of installation of IoT. & 12 & 7.5 \\
Complex implementation. & 1 & 0.6 \\
\hline
\end{tabular}

Note: $\mathrm{n}=40$

implementing IoT. Out of 158 halal agro-food SMEs involved in this study, only 40 (25\%) of halal agro-food SMEs responded to statements about challenges and majority of them $(15,9.4 \%)$ addressed difficulties in getting trusted information over halal raw materials through the information network as one of the main IoT challenges. There were $7(4.4 \%)$ of the halal agro-food SMEs also highlighted that IoT was not suitable to be implemented by small, medium and micro-enterprises while $5(3.1 \%)$ of the halal agro-food SMEs were concerned on IoT information security. There were 12 (7.5\%) of the halal agro-food SMEs addressed high cost for installation of IoT devices in business premises, maintenance costs, and there was only $1(0.6 \%)$ of halal agro-food SMEs addressed complex implementation of IoT as one of the challenges. These results showed that halal agro-food SMEs are facing similar challenges to adopting technologies like other SMEs. Therefore, it is very important to remove these challenges as suggested by Marasini et al. (2008); Martinsuo and Luomaranta (2018) to improve the adoption of technology among SMEs.

\section{Conclusion}

In Malaysia, halal agro-food SMEs play a significant role in serving halal food for both Muslim and nonMuslim consumers. The emergence of advanced technology requires halal agro-food SMEs to be on par with other industries and to remain competitive in the global markets. The halal agro-food SMEs should realize the benefits of adopting IoT in managing halal business activities. Since only the minority of halal agro-based SMEs in this study showed a high knowledge level on IoT, authorized bodies must initiate efforts to deliver knowledge on advanced technologies to the SMEs. On the other hand, halal agro-food SMEs are encouraged to find their own initiatives to stay align and keep up with the current business trends.

IoT is believed to reduce mental and physical efforts and help to improve business performance. Difficulties of getting trusted halal information through information network and high cost of installation of IoT devices in business premises are among challenges that most frequently addressed by halal agro-food SMEs.
Nonetheless, this study concludes that Malaysian halal agro-food SMEs have the high potential for taking advantage of technological advancement despite the claimed challenges on IoT adoption. By providing proper training and knowledge transfer programs on IoT, it is believed that these halal agro-food SMEs could reap the long-term benefits of IoT.

\section{Acknowledgment}

We thank the Ministry of Education (MOE) for the financial support through the Malaysia Higher Education Consortium of Halal Institute (KIHIM) (Reference number: JPT. S(BKPI)2000/016/018/09 Jld.2 (44), JPT. S(BKPI)2000/016/018/05 Jld.4 (60); Vote No: 6300912).

\section{References}

Ahmad Tarmizi., H.A., Kamarulzaman, N.H., Latiff, I. A. and Rahman, A.A. (2014). Factors influencing readiness towards halal logistics among food-based logistics players in Malaysia. UMK Procedia, 1, 4249. https://doi.org/10.1016/j.umkpro.2014.07.006

Ahmad Tarmizi, H.A., Kamarulzaman, N.H. and Latiff, I.A. (2014). Factors behind third-party logistics providers readiness towards halal logistics. International Journal of Supply Chain Management, 3(2), 53-62.

Al-ajam, A.S. and Nor, K. (2015). Challenges of adoption of internet banking service in Yemen. International Journal of Bank Marketing, 33(2), 178 -194. https://doi.org/10.1108/IJBM-01-2013-0001

Ajzen, I. (1991). The theory of planned behavior. Organizational Behavior and Human Decision Processes, 50(2), 179-211. https:// doi.org/10.1016/0749-5978(91)90020-T

Bhaskaran, S. (2013). Structured case studies: information communication technology adoption by small-to-medium food enterprise. British Food Journal, 115(3), 425-447. https:// doi.org/10.1108/00070701311314237

Brand, M.J. and Huizingh, E.K.R. (2008). Into the drivers of innovation adoption: what is the impact of the current level of adoption? European Journal of Innovation Management, 11(1), 5-24. https:// 
doi.org/10.1108/14601060810845204

Buabeng-andoh, C. (2018). Predicting students' intention to adopt mobile learning technology acceptance model. Journal of Research in Innovative Teaching and Learning, 11(2), 178-191. https:// doi.org/10.1108/JRIT-03-2017-0004

Chibelushi, C. and Costello, P. (2009). Challenges facing W. Midlands ICT-oriented SMEs. Journal of Small Business and Enterprise Development, 16(2), 210239. https://doi.org/10.1108/14626000910956029

Dang, V. and Pham, T. (2018). An empirical investigation of consumer perceptions of online shopping in an emerging economy Adoption theory perspective. Asia Pacific Journal of Marketing and Logistics, 30(4), 952-971. https://doi.org/10.1108/ APJML-01-2018-0038

Davis, F.D. (1989). Perceived Usefulness, Perceived Ease of Use, and User Acceptance of Information Technology. Information Technology, 13(3), 319340. https://doi.org/10.2307/249008

Del Giudice, M. (2016). Discovering the Internet of Things (IoT) within the business process management. Business Process Management Journal, 22(2), 263-270. https://doi.org/10.1108/ BPMJ-12-2015-0173

Dutton, H.W. (2014). Putting things to work: social and policy challenges for the internet of things. Info, 16 (3), 1-21. https://doi.org/10.1108/info-09-2013-0047

Feher, A. and Towell, E. (2010). Business use of the Internet. Internet Research, 7(2), 195-200. https:// doi.org/10.1108/10662249710171832

Ghobakhloo, M., Arias-aranda, D. and Benitez-amado, J. (2011). Adoption of e-commerce applications in SMEs. Industrial Management and Data System, 111(8), 1238-1269. https:// doi.org/10.1108/02635571111170785

Haddud, A., DeSouza, A., Khare, A. and Lee, H. (2017). Examining potential benefits and challenges associated with the internet of things integration in supply chains. Journal of Manufacturing Technology Management, 28(8), 1055-1085. https:// doi.org/10.1108/JMTM-05-2017-0094

Hanafizadeh, P., Behboudi, M., Ahadi, F. and Varkani, F.G. (2012). Internet advertising adoption: a structural equation model for Iranian SMEs. Internet Research, 22(4), 499-526. https:// doi.org/10.1108/10662241211251015

Hamill, J. (1997). The internet and international marketing. International Marketing Review, 14(5), 300-323. doi.org/10.1108/02651339710184280

Ibrahim, H.R. and Mokhtarudin, M.Z.H. (2010).
Fraudulent quality labeling: case of halal labeling. China-USA Business Review, 9(9), 41-70.

Iskandar, M., Tan, I., Razali, R.N. and Husny, Z.J. (2012). The adoption of halal transportations technologies for halal logistics service providers in Malaysia. International Journal of Transport and Vehicle Engineering, 6(3), 2012 467-474.

Kamarulzaman, N.H. and Eglese, R.W. (2016). The potential use of e-procurement in the Malaysian palm oil industry supply chain. Journal of Social Sciences and Humanities, 21, 95-108.

Kamarulzaman, N.H. and Mohamed, Z. (2013). Application of e-procurement technologies for selecting suppliers of agro-based SMEs in Malaysia. International Journal of Economics and Management, 7(1), 45-66.

Kamarulzaman, N.H. and Nawi, N.M. (2009). The use of internet applications in managing logistics activities among palm oil industry participants. International Journal of Economics and Management, 3(2), 262-277.

Karipidis, P., Athanassiadis, K., Aggelopoulos, S. and Giompliakis, E. (2009). Factors affecting the adoption of quality assurance systems in small food enterprises. Food Control, 20(2), 93-98. https:// doi.org/10.1016/j.foodcont.2008.02.008

Lada, S., Tanakinjal, G.H. and Amin, H. (2011). Predicting intention to choose halal products using theory of reasoned action. International Journal of Islamic and Middle Eastern Finance and Management, 2(1), 66-67. https:// doi.org/10.1108/17538390910946276

Li, S., Tryfonas, T. and Li, H. (2016). The internet of things: a security point of view. Internet Research, 26(2), 337-359. https://doi.org/10.1108/IntR-072014-0173

Li, Z., Liu, G., Liu, L., Lai, X. and Xu, G. (2017). IoTbased tracking and tracing platform for prepackaged food supply chain. Industrial Management and Data Systems, 117(9), 1906-1916. https://doi.org/10.1108/ IMDS-11-2016-0489

Lindsay, R., Jackson, T.W. and Cooke, L. (2011). Adapted technology acceptance model for mobile policing Adapted technology acceptance model for mobile policing. Journal of Systems and Information Technology, 13(4), 389-407. https:// doi.org/10.1108/13287261111183988

Lu, J., Yu, C.S., Liu, C. and Yao, J.E. (2003). Technology acceptance model for wireless Internet. Internet Research: Electronic Networking Application and Policy, 13(3), 206-222. https:// doi.org/10.1108/10662240310478222 
Marasini, R., Ions, K. and Ahmad, M. (2008). Assessment of e-business adoption in SMEs: A study of manufacturing industry in the UK North East region. Journal of Manufacturing Technology Management, 19(5), 627-644. https:// doi.org/10.1108/17410380810877294

Martinsuo, M. and Luomaranta, T. (2018). Adopting additive manufacturing in SMEs: exploring the challenges and solutions. Journal of Manufacturing Technology Management, 29(6), 937-957. https:// doi.org/10.1108/JMTM-02-2018-0030

Molinillo, S. and Japutra, A. (2017). Organizational adoption of digital information and technology: a theoretical review. The Bottom Line, 30(1), 33-46. https://doi.org/10.1108/BL-01-2017-0002

Nainy, R. (2017). Industry 4.0 and its implications to SMEs. Retrieved on 12 August 2019 from website: https://www.miti.gov.my/miti/resources/ Industry4Point0/

SMECorp_Industry_4_and_Implications_to_SMEs.p df

Parmentola, A., Simoni, M., Tutore, I., Parmentola, A., Simoni, M. and Tutore, I. (2018). Fast and furious : how the open vs closed dilemma affects the technology diffusion dynamic. Management Decision, 56(4), 867-890. https://doi.org/10.1108/ MD-01-2017-0071

Parry, G.C., Brax, S.A., Maull, R.S. and Ng, I.C.L. (2016). Operationalising IoT for reverse supply: the development of use-visibility measures. Supply Chain Management: An International Journal, 21 (2), 228-244. https://doi.org/10.1108/SCM-10-20150386

Pipitwanichakarn, T. and Wongtada, N. (2019). Leveraging the technology acceptance model for mobile commerce adoption under distinct stages of adoption. Asia Pacific Journal of Marketing and Logistics, 1-22. https://doi.org/10.1108/APJML-102018-0448

Paul, P. (1996). Marketing on the Internet. Journal of Consumer Marketing, 13(4), 27-39. https:// doi.org/10.1108/07363769610124528

Rajendran, S.D. and Kamarulzaman, N.H. (2018). The Influences of Islamic Practices on Halal Supply Chain Integrity: A Study from the Perspective of Herbal Food SMEs in Malaysia. International Journal of Supply Chain Management, 8(3), 827832.

Ramdani, B., Chevers, D. and Williams, A. (2013). SMEs ' adoption of enterprise applications. Journal of Small Business and Enterprise Development, 20 (4), 735-753. https://doi.org/10.1108/JSBED-12-

\section{1-0035}

Rankin, G. and Stokes, M. (1998). Statistical analysis of reliability studies. Clinical Rehabilitation, 12(3), 187 -199. https://doi.org/10.1191/026921598672178340

Rezaei, M., Shirazi, M. and Karimi, B. (2017). IoT-based framework for performance measurement. Industrial Management and Data Systems, 117(4), 688-712. https://doi.org/10.1108/IMDS-08-2016-0331

Rogers, E.M. (1995). Diffusion of innovations. $4^{\text {th }} \mathrm{ed}$. 4th ed. New York, NY: The Free Press.

Rose, K., Eldridge, S. and Chapin, L. (2015). The Internet of Things: An Overview. The Internet Society, 1-80.

Sanlier, N. and Konaklioglu, E. (2012). Food safety knowledge, attitude and food handling practices of students. British Food Journal, 114(4), 469-480. https://doi.org/10.1108/00070701211219504

Simmons, G.J., Durkin, M.G., Mcgowan, P. and Armstrong, G.A. (2007). Determinants of internet adoption by SME agri-food companies. Journal of Small Business and Enterprise Development, 14(4), 620-640.

https:// doi.org/10.1108/14626000710832730

SME Corporation. (2018). SME Corp Annual Report 2017/2018. 1-136.

Tan, K., Chong, S., Lin, B. and Eze, U. (2010). Internetbased ICT adoption among SMEs. Journal of Enterprise Information Management, 23(1), 27-55. https://doi.org/10.1108/17410391011008897

Tan, K.S., Chong, S.C., Lin, B. and Eze, U.C. (2009). Internet-based ICT adoption: evidence from Malaysian SMEs. Industrial Management and Data Systems, $\quad 109(2), \quad 224-244 . \quad \mathrm{https} / / /$ doi.org/10.1108/02635570910930118

Venkatesh, V. and Bala, H. (2008). Technology acceptance model 3 and a research agenda on interventions. Decision Sciences, 39(2), 273-315. https://doi.org/10.1111/j.1540-5915.2008.00192.x

Venkatesh, V. and Davis, F. (2000). A theoretical extension of the technology acceptance model: four longitudinal field studies. Management Science, 46 (2), 186-204. https://doi.org/10.1287/ mnsc.46.2.186.11926

Wallace, L.G. and Sheetz, S.D. (2014). The adoption of software measures: a technology acceptance model (TAM) perspective. Information and Management, 51(2), 249-259. https://doi.org/10.1016/ j.im.2013.12.003

Wilkesmann, M. and Wilkesmann, U. (2018). Industry 4.0-organizing routines or innovations? VINE Journal of Information and Knowledge Management Systems, 48(2), 238-254. https://doi.org/10.1108/ 
VJIKMS-04-2017-0019

Yan, B., Yan, C., Ke, C. and Tan, X. (2016). Information sharing in supply chain of agricultural products based on the Internet of Things. Industrial Management and Data Systems, 116(7), 1397-1416. https://doi.org/10.1108/IMDS-12-2015-0512

Zhang, Y., Zhao, L. and Qian, C. (2017). Modeling of an IoT-enabled supply chain for perishable food with two-echelon supply hubs. Industrial Management and Data Systems, 117(9), 1890-1905. https:// doi.org/10.1108/IMDS-10-2016-0456 